\title{
Lithium-ion diffusion mechanisms in the battery anode material $\mathrm{Li}_{1+x} \mathrm{~V}_{1-x} \mathrm{O}_{2} \dagger$
}

Cite this: Phys. Chem. Chem. Phys., 2014, 16, 21114

Received 16th April 2014, Accepted 30th June 2014

DOI: $10.1039 / \mathrm{c} 4 \mathrm{cp} 01640 \mathrm{~h}$

www.rsc.org/pccp

\begin{abstract}
Pooja M. Panchmatia, ${ }^{\text {ab }}$ A. Robert Armstrong, ${ }^{c}$ Peter G. Bruce ${ }^{c}$ and M. Saiful Islamª
Layered $\mathrm{Li}_{1+x} \mathrm{~V}_{1-x} \mathrm{O}_{2}$ has attracted recent interest as a potential low voltage and high energy density anode material for lithium-ion batteries. A greater understanding of the lithium-ion transport mechanisms is important in optimising such oxide anodes. Here, stoichiometric $\mathrm{LiVO}_{2}$ and $\mathrm{Li}$-rich $\mathrm{Li}_{1.07} \mathrm{~V}_{0.93} \mathrm{O}_{2}$ are investigated using atomistic modelling techniques. Lithium-ion migration is not found in $\mathrm{LiVO}_{2}$, which has also previously shown to be resistant to lithium intercalation. Molecular dynamics simulations of lithiated non-stoichiometric $\mathrm{Li}_{1.07+y} \mathrm{~V}_{0.93} \mathrm{O}_{2}$ suggest cooperative interstitial $\mathrm{Li}^{+}$diffusion with favourable migration barriers and diffusion coefficients $\left(D_{\mathrm{Li}_{\mathrm{i}}}\right)$, which are facilitated by the presence of lithium in the transition metal layers; such transport behaviour is important for high rate performance as a battery anode.
\end{abstract}

\section{Introduction}

The revolution in portable electronic devices has been powered by rechargeable lithium-ion batteries. Alternative electrode materials for new generations of lithium batteries are generating considerable research activity, particularly for large-scale applications (such as electric vehicles and grid storage). ${ }^{1-9}$ Graphite is currently the dominant anode material in Li-ion batteries. Metal oxide anodes such as $\mathrm{TiO}_{2}(\mathrm{~B})$ are attracting interest since they can offer twice the volumetric energy density of graphite. ${ }^{10-12}$ However, the anode voltage for titanium oxides

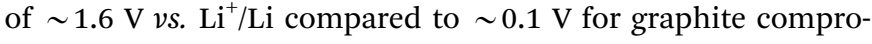
mises the cell voltage and hence energy storage.

Recent studies have shown that $\mathrm{Li}$ can be intercalated into the layered oxide $\mathrm{Li}_{1+x} \mathrm{~V}_{1-x} \mathrm{O}_{2}$, at an unusually low voltage of $\sim 0.1 \mathrm{~V} v$ s. $\mathrm{Li}^{+} / \mathrm{Li}^{13-20}$ with a theoretical volumetric capacity of $1360 \mathrm{~mA} \mathrm{~h} \mathrm{~cm}{ }^{-3}$ compared to graphite at $790 \mathrm{~mA} \mathrm{~h} \mathrm{~cm}{ }^{-3}$. Previously we investigated the intercalation process for $\mathrm{Li}_{1+x} \mathrm{~V}_{1-x} \mathrm{O}_{2}$ and in particular the key role that non-stoichiometry or excess lithium $(x>0)$ plays in switching on intercalation. ${ }^{16}$ Lithium does not intercalate into stoichiometric layered $\mathrm{LiVO}_{2}$ (Fig. 1). However, substituting a small amount of the $\mathrm{V}$ on the transition metal sites by Li (typically $\mathrm{Li}_{1.07} \mathrm{~V}_{0.93} \mathrm{O}_{2}$ ) is sufficient to promote a two-phase intercalation process at a potential of $\sim 0.1 \mathrm{~V}$.

Other recent studies on this system ${ }^{17}$ include an investigation of doping on the $\mathrm{V}$ site with $\mathrm{Cr}$ or Fe leading to improved

\footnotetext{
${ }^{a}$ Department of Chemistry, University of Bath, Bath BA2 7AY, UK. E-mail: m.s.islam@bath.ac.uk

${ }^{b}$ Department of Chemical Sciences, University of Huddersfield, Huddersfield, UK

${ }^{c}$ School of Chemistry, University of St. Andrews, St. Andrews, Fife, UK

$\dagger$ Electronic supplementary information (ESI) available. See DOI: 10.1039/ c4cp01640h
}

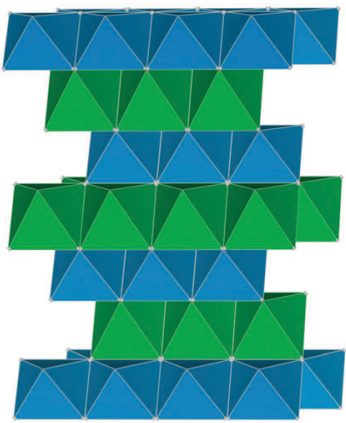

(a)

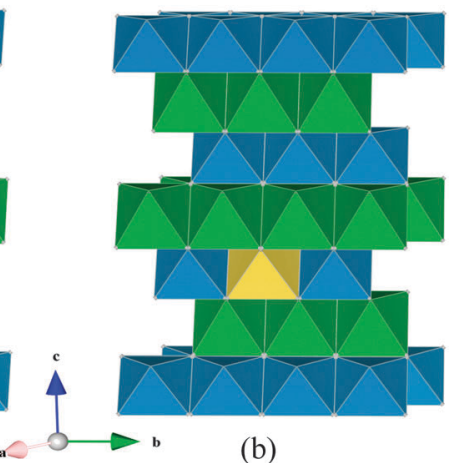

(b)
Fig. 1 Schematic representation of the layered structures of (a) $\mathrm{LiVO}_{2}$, and (b) $\mathrm{Li}_{1.07} \mathrm{~V}_{0.93} \mathrm{O}_{2}$. Key: $\mathrm{LiO}_{6}$ octahedra (green); $\mathrm{VO}_{6}$ octahedra (blue); $\mathrm{Li}$ on $\mathrm{V}$ site (yellow).

rate capabilities and cyclability. A combination of solid state NMR, pair distribution function analysis and density functional theory calculations has provided further insights into the crystal and electronic structures of $\mathrm{Li}_{1+x} \mathrm{~V}_{1-x} \mathrm{O}_{2}$, indicating magnetically-induced distortions of the $\mathrm{V}$ sublattice to form trimers. ${ }^{18}$

To fully understand the factors influencing the electrochemical behaviour of the $\mathrm{Li}_{1+x} \mathrm{~V}_{1-x} \mathrm{O}_{2}$ anode material it is clear that greater insight into the underlying lithium transport properties is needed at the atomic scale. Indeed, a major puzzle is what is the atomistic mechanism controlling lithium-ion diffusion in this new oxide anode? Such transport features are important factors for charge/ discharge rates and high power, but are often difficult to determine from experimental methods. Here, we extend our previous electrode work with a combination of energy minimization and molecular dynamics (MD) simulation techniques to probe, for the 
first time, the lithium-ion diffusion mechanisms in the vanadate material. In particular, the results comparing stoichiometric $\mathrm{LiVO}_{2}$ and Li-rich $\mathrm{Li}_{1.07} \mathrm{~V}_{0.93} \mathrm{O}_{2}$ from long time-scale $\mathrm{MD}$ provide new insights into the mechanistic features of interstitial lithium-ion transport.

\section{Methods}

Atomistic modelling techniques are well suited to the investigation of defect and transport properties and have been applied successfully to a variety of studies on lithium battery materials. ${ }^{21-26}$ In the present study, potentials-based energy minimization and molecular dynamics (MD) were employed. ${ }^{25-27}$ The GULP code ${ }^{28}$ was used for the interatomic potential refinement, and the Mott-Littleton ${ }^{29}$ method was used to investigate the isolated point defects. The interactions between ions were represented in terms of a long-range Coulombic term plus an analytical function representing short-range repulsive and van der Waals forces. The empirically-derived potential parameters for $\mathrm{Li}-\mathrm{O}, \mathrm{V}-\mathrm{O}$ and $\mathrm{O}-\mathrm{O}$ were transferred from our previous successful study of the $\mathrm{LiVO}_{2}$ system. ${ }^{16}$ The Buckingham shell-model potentials used in this study are presented in ESI, $\uparrow$ Table S1.

The MD technique consists of an explicit dynamical simulation of the ensemble of ions for which Newton's equations of motion are solved (and were carried out using the DLPOLY 2.20 code). ${ }^{27}$ For this work two key structural compositions were compared: stoichiometric $\mathrm{LiVO}_{2}$ and the lithiated nonstoichiometric $\mathrm{Li}_{1.07+y} \mathrm{~V}_{0.93} \mathrm{O}_{2}$ (where $y=0.09$ ). The $\mathrm{LiVO}_{2}$ simulation box was constructed using a $10 \times 10 \times 2$ P1 supercell consisting of 2400 atoms. Our previous work showed that $\mathrm{Li}$ intercalation into the Li-rich $\mathrm{Li}_{1.07} \mathrm{~V}_{0.93} \mathrm{O}_{2}$ phase was energetically more favourable and that the $\mathrm{Li}$ interstitials preferred to go on a tetrahedral site adjacent to a $\mathrm{Li}$ on a vanadium site. ${ }^{16}$ The initial $\mathrm{Li}_{1.07+y} \mathrm{~V}_{0.93} \mathrm{O}_{2}$ configuration contained $10 \% \mathrm{Li}$ interstitial ions placed on these tetrahedral sites leading to a total of 2454 atoms in the supercell. The charge-compensation for $\mathrm{Li}$ on the $\mathrm{V}$ sites and Li interstitials was delocalised across all the $\mathrm{V}$ ions to make the supercell charge neutral. More than three initial configurations of the lithiated lithium vanadium oxide were explored via full bulk optimisations; their energetic stabilities were compared and the lowest energy configuration was used for the subsequent MD simulations.

After initial equilibration (100000 steps), MD simulations were performed with a 0.5 fs time step for long runs of $1.1 \mathrm{~ns}$ at temperatures in the range 200-600 K (Nóse-Hoover thermostat $^{27}$ ) at intervals of $100 \mathrm{~K}$. The NPT ensemble was used to allow for any thermal expansion after which the NVT ensemble was employed for the full production runs of $1.1 \mathrm{~ns}$, which are important for good statistics. Such potentials-based MD techniques have been applied to other lithium battery materials ${ }^{23,24}$ and to oxide-ion conductors for solid oxide fuel cells. ${ }^{30}$ It is worth remarking that we are employing much larger supercells and an order of magnitude longer timescales than the majority of $a b$ initio MD simulations.

\section{Results and discussion}

\subsection{Structures and defect chemistry}

$\mathrm{LiVO}_{2}$ and $\mathrm{Li}_{1.07} \mathrm{~V}_{0.93} \mathrm{O}_{2}$ are both ccp structures (space group $R \overline{3} m$ ) with alternating $\mathrm{LiO}_{6}$ and $\mathrm{VO}_{6}$ layers shown schematically in Fig. 1; the lithium present in the transition metal layers in $\mathrm{Li}_{1.07} \mathrm{~V}_{0.93} \mathrm{O}_{2}$ is highlighted. The modelling study first attempted to reproduce the observed crystal structures. A comparison between the calculated unit cell parameters based on effective potentials and those of the experimental structure is given in Table 1. The calculated unit cell parameters deviate from experiment by at most $1.9 \%$, and in most cases much less; the same is found for the $\mathrm{Li}-\mathrm{O}$ and $\mathrm{V}-\mathrm{O}$ bond lengths. This reproduction of the structures of both $\mathrm{LiVO}_{2}$ and $\mathrm{Li}_{1.07} \mathrm{~V}_{0.93} \mathrm{O}_{2}$ compositions gives us confidence that the interatomic potential model can be used reliably in the defect and migration calculations. In ESI, $\dagger$ we have listed the calculated elastic and dielectric constants for $\mathrm{LiVO}_{2}$ and $\mathrm{Li}_{1.07} \mathrm{~V}_{0.93} \mathrm{O}_{2}$. Although there are no experimental data for the $\mathrm{LiVO}_{2}$ system for direct comparison, our calculated values are consistent with observed and DFT values for similar layered oxides ${ }^{31}$ including static dielectric constants for $\mathrm{LiCoO}_{2}$.

A series of isolated point defect (vacancy and interstitial) energies were then calculated, and combined to give the relative energies of formation of the Li Frenkel defect. We also examined the Li/M "anti-site" pair defect, which involves the exchange of a V ion (radius $0.64 \AA$ ) with a Li ion (radius $0.76 \AA$ ); this type of defect is worth investigating since cation exchange effects have been observed in other layered oxide electrodes. ${ }^{1,2}$

Table 2 lists the formation energies of Li Frenkel and antisite defects in the two compositions. The high unfavourable energies suggest that the inability to intercalate into stoichiometric $\mathrm{LiVO}_{2}$ is not due to the presence of site-exchange disorder involving $\mathrm{V}$ ions in the alkali metal layers pinning them together; this result is in agreement with previous structural studies indicating that there is no $\mathrm{V}$ in the Li layers of

Table 1 Comparison of experimental ${ }^{16}$ and calculated structural parameters for $\mathrm{LiVO}_{2}$ and $\mathrm{Li}_{1.07} \mathrm{~V}_{0.93} \mathrm{O}_{2}$. Calculated elastic and dielectric properties have been presented in ESI, Table S2

\begin{tabular}{llll}
\hline & Expt. & Calc. & \\
\hline$(\mathrm{a}) \mathrm{LiVO}_{2}(R \overline{3} m)$ & & & \\
$a / \AA$ & 2.8377 & 2.8608 & 0.023 \\
$b / \AA$ & 2.8377 & 2.8608 & 0.023 \\
$c / \AA$ & 14.8230 & 14.5516 & -0.271 \\
$\alpha / \beta \mathrm{deg}$ & 90.0 & 90.0 & 0.0 \\
$\gamma / \mathrm{deg}$ & 120.0 & 120.0 & 0.0 \\
$\mathrm{Li}-\mathrm{O} / \AA$ & 2.102 & 2.103 & 0.001 \\
$\mathrm{~V}-\mathrm{O} / \AA$ & 2.004 & 2.905 & 0.054 \\
$\mathrm{O}-\mathrm{O} / \AA$ & 2.830 & & 0.075 \\
& & & \\
$(\mathrm{~b}) \mathrm{Li}{ }_{1.07} \mathrm{~V}_{0.93} \mathrm{O}_{2}(R \overline{3} m)$ & 2.9370 & 0.094 \\
$a / \AA$ & 2.8920 & 0.049 \\
$b / \AA$ & 2.8430 & 14.6355 & -0.132 \\
$c / \AA$ & 2.8430 & 90.0 & 0.0 \\
$\alpha / \beta$ deg & 14.7675 & 120.0 & 0.0 \\
$\gamma / \mathrm{deg}$ & 90.0 & 2.064 & 0.044 \\
$\mathrm{Li}-\mathrm{O} / \AA$ & 120.0 & 2.030 & -0.016 \\
$\mathrm{Li}+{ }^{+} \mathrm{V}-\mathrm{O} / \AA$ & 2.020 & 2.030 & -0.007 \\
$\mathrm{~V}-\mathrm{O} / \AA$ & 2.046 & 2.832 & 0.002 \\
$\mathrm{O}-\mathrm{O} / \AA$ & 2.037 & & \\
& 2.834 & &
\end{tabular}


Table 2 Formation energies of lithium Frenkel and anti-site defects (The reaction equations can be found in the ESI.)

\begin{tabular}{lll}
\hline Compound & Frenkel defect energy (eV) & Antisite defect energy (eV) \\
\hline $\mathrm{LiVO}_{2}$ & 3.58 & 3.44 \\
$\mathrm{Li}_{1.07} \mathrm{~V}_{0.93} \mathrm{O}_{2}$ & 1.67 & 1.36
\end{tabular}

$\mathrm{LiVO}_{2}$. The site exchange energy in $\mathrm{Li}_{1.07} \mathrm{~V}_{0.93} \mathrm{O}_{2}$ is the most favourable, although the magnitude still suggests that intrinsic concentrations will not be significant. The calculated defect energies also suggest that intrinsic lithium vacancies and interstitials are unlikely to be found in stoichiometric $\mathrm{LiVO}_{2}$.

\subsection{Li ion diffusion}

Examination of the Li-ion transport properties of $\mathrm{Li}_{1+x} \mathrm{~V}_{0.93} \mathrm{O}_{2}$ is of vital importance when considering electrode kinetics. Of primary interest here is information on the atomistic mechanism of lithium-ion diffusion, which is difficult to probe purely by experimental methods. Molecular dynamics (MD) techniques are well suited to probing transport mechanisms, especially cooperative or correlated ion motion. Here, MD calculations over long simulation time scales were carried out at temperatures more than covering typical battery operating temperatures for the two compositions for direct comparison: stoichiometric $\mathrm{LiVO}_{2}$ and the lithiated non-stoichiometric $\mathrm{Li}_{1.07+y} \mathrm{~V}_{0.93} \mathrm{O}_{2}(y=0.09)$.

First, the mean squared displacements (MSDs), $\left\langle[r(t)]^{2}\right\rangle$, of lithium ions have been resolved and shown in Fig. 2; the results clearly show that there is significant lithium-ion diffusion only in the Li-rich composition. For $\mathrm{LiVO}_{2}$ the MSD of the Li-ions tends rapidly to a constant value and confirms that there is no ion diffusion in this stoichiometric composition.

The Li-ion diffusion coefficient $\left(D_{\mathrm{Li}}\right)$ can be derived from the MSD data given by $D=(1 / 6 t)\left\langle[r(t)]^{2}\right\rangle$. We calculate a $D_{\mathrm{Li}}$ value of about $10^{-9} \mathrm{~cm}^{2} \mathrm{~s}^{-1}$ for $\mathrm{Li}_{1.07+y} \mathrm{~V}_{0.93} \mathrm{O}_{2}(y=0.09)$ at $300 \mathrm{~K}$. Although there are currently no measured diffusion data for direct comparison, the magnitude is comparable to other electrode materials; for example, graphite has lithium diffusivity of about $10^{-8}$ to $10^{-9} \mathrm{~cm}^{2} \mathrm{~s}^{-1}, 32$ and experimental diffusion coefficients of $10^{-8}$ to $10^{-11} \mathrm{~cm}^{2} \mathrm{~s}^{-1}$ have been reported ${ }^{33}$ for $\mathrm{Li}^{+}$diffusion in layered oxide cathodes such as $\mathrm{LiCoO}_{2}$ and $\mathrm{Li}(\mathrm{Ni}, \mathrm{Mn}, \mathrm{Co}) \mathrm{O}_{2}$.

An Arrhenius plot $(\ln D$ versus $1 / T)$ for lithiated $\mathrm{Li}_{1.16} \mathrm{~V}_{0.93} \mathrm{O}_{2}$ is presented in Fig. 3. Analysis of such data provides an
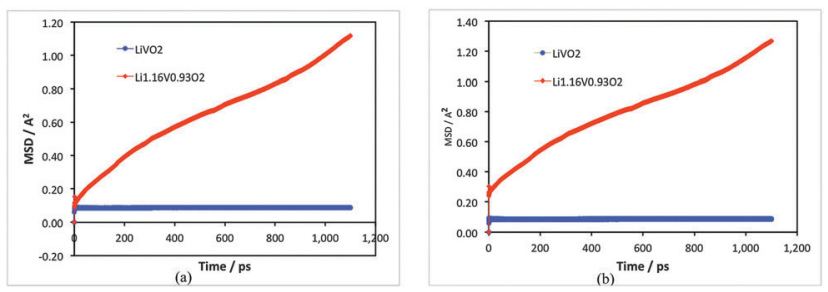

Fig. 2 Mean squared displacement (MSD) plots for $\mathrm{LiVO}_{2}$ (blue) and $\mathrm{Li}_{1.07+y} \mathrm{~V}_{0.93} \mathrm{O}_{2}$ (red) for $1.1 \mathrm{~ns}$ at (a) $400 \mathrm{~K}$ and (b) $500 \mathrm{~K}$.

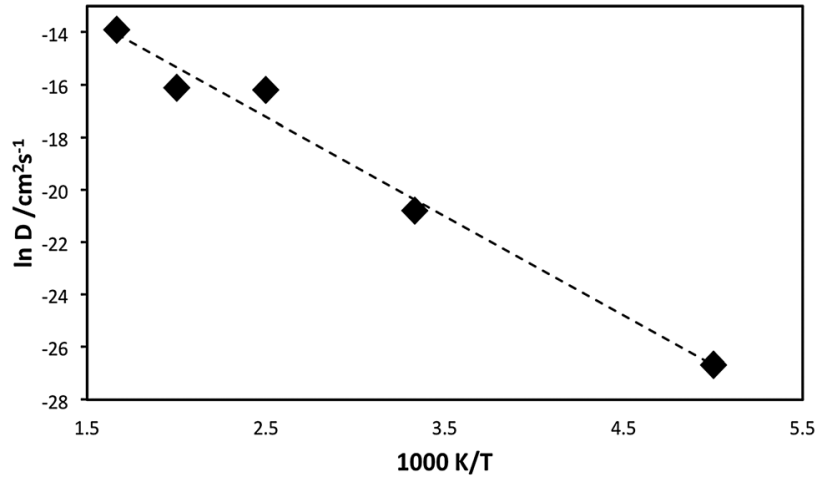

Fig. 3 Arrhenius plot ( $\ln D$ vs. $1 / T$ ) for $\mathrm{Li}_{1.07+y} \mathrm{~V}_{0.93} \mathrm{O}_{2}$.

estimate of the migration activation energy $\left(E_{\text {act }}\right)$ using the standard Arrhenius relation:

$$
D=A \exp \left(-E_{\text {act }} / k T\right)
$$

A migration activation energy of $0.32 \mathrm{eV}$ is derived, indicating high Li ion mobility in this Li-rich oxide anode, which is important for good rate capability. Despite the lack of Li ion conductivity data for direct comparison, our calculated migration energy is compatible with low activation energies for other layered oxides such as $\mathrm{Li}_{x} \mathrm{Co}_{0.95} \mathrm{Mg}_{0.05} \mathrm{O}_{2},{ }^{34} \mathrm{Li}_{x} \mathrm{CoO}_{2}{ }^{26}$ and $\mathrm{Li}_{x}$ $\mathrm{NiO}_{2},{ }^{35}$ albeit for $\mathrm{Li}$ vacancy migration.

Scatter or density plots of the accumulated density of lithium ion trajectories over the simulated time scale enables useful visualization of the migration pathways and the lattice regions most frequently traversed by the mobile Li-ions. Fig. $4 \mathrm{a}$ shows the starting configuration of the $\mathrm{Li}_{1.07+y} \mathrm{~V}_{0.93} \mathrm{O}_{2}(y=0.09)$ structure where the $\mathrm{Li}_{\mathrm{V}}^{+}$atoms are in the vanadium layers and the interstitial lithiums are on tetrahedral sites. As shown previously, ${ }^{16}$ substitution of Li for $\mathrm{V}$ on the octahedral transition metal sites renders tetrahedral sites in the alkali metal layers energetically accessible by $\mathrm{Li}$.

The lithium diffusion density plots and final configuration of ions in $\mathrm{Li}_{1.07+y} \mathrm{~V}_{0.93} \mathrm{O}_{2}(y=0.09)$ at the end of the MD simulation are shown in Fig. $4 \mathrm{~b}$. The diffuse distribution and overlapping of different lithium positions indicate that numerous different lithium ions are moving between octahedral lattice and tetrahedral interstitial sites. These results show that long-range lithium-ion migration is highly anisotropic, restricted to within the lithium layers adjacent to vanadium layers that contain a small amount of lithium ions. Interestingly, there is also evidence of ion migration between adjacent layers via the lithium ions on the $\mathrm{V}$ sites. In contrast, the lithium layers that are not adjacent to Li on $\mathrm{V}$ sites, do not exhibit diffusion within or across the layers. A key feature is that the Li-rich composition with $\mathrm{Li}$ on $\mathrm{V}$ sites plays a vital role in not only switching on the lithium intercalation process, ${ }^{16}$ but also in aiding facile lithiumion diffusion.

A major thrust of fundamental transport studies has been the examination of the atomistic mechanisms controlling bulk transport phenomena. Indeed, the unravelling of mechanistic 


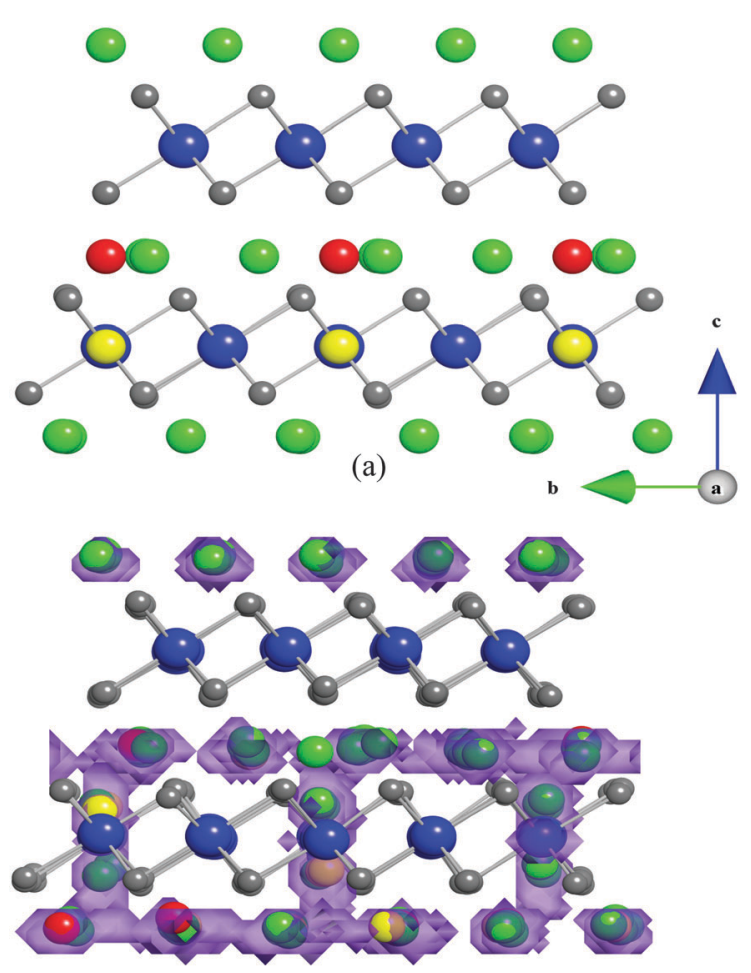

(b)

Fig. 4 (a) Ion positions of the initial configuration of $\mathrm{Li}_{1.07+y} \mathrm{~V}_{0.93} \mathrm{O}_{2}$ $(y=0.09)(b) M D$ density plot of mobile lithium ions (purple) overlayed on a snapshot of the final configuration after $1.1 \mathrm{~ns}$. Key: octahedral Li (green); octahedral V (blue); Li on V site (yellow); interstitial Li (red); O (grey).

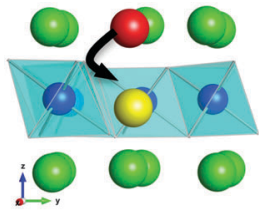

(i)

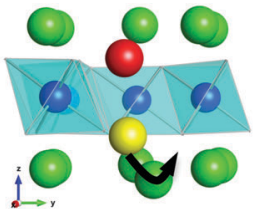

(ii)

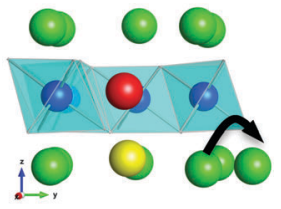

(iii)
Fig. 5 MD simulation snapshots of ion positions showing the cooperative knock-on like mechanism: the migrating interstitial $\mathrm{Li}^{+}$(red) displaces the $\mathrm{Li}$ in the $\mathrm{V}$ layer (yellow) into an adjacent interstitial position which in turn leads to further Li migration. The oxygen atoms have been omitted for clarity. Key: octahedral Li (green); octahedral V (blue).

detail at the microscopic level is a powerful feature of the MD technique. Fig. 5 shows a series of snapshots of the lithium ions as they migrate within the alkali-ion layer and via the $\mathrm{Li}$ ions in the vanadium layers. This illustration suggests that lithium-ion diffusion takes place by a cooperative interstitialcy or knock-on type mechanism in which the migrating interstitial Li-ion displaces the $\mathrm{Li}$ in the $\mathrm{V}$ layer into a neighbouring interstitial position in the alkali-metal layer. Such a cooperative type mechanism facilitates lithium-ion diffusion despite the lack of open conduction pathways. Similar cooperative mechanisms have been discussed in connection with lithium migration in $\mathrm{LiMgSO}_{4} \mathrm{~F}^{24}$ and with interstitial oxide-ion conduction in electrolytes for solid oxide fuel cells, ${ }^{30}$ but have not been widely elucidated in Li-rich layered oxides.

\section{Conclusions}

Atomic-scale mechanistic features of Li-ion transport in vanadium oxide anode materials have been investigated, revealing three main results.

First, the defect formation energies indicate that the inability to intercalate into stoichiometric $\mathrm{LiVO}_{2}$ is not due to the presence of cation exchange disorder involving $\mathrm{V}$ ions in the lithium ion layers pinning them together, which is in agreement with structural studies. It is known that the Li-rich composition $\mathrm{Li}_{1.07} \mathrm{~V}_{0.93} \mathrm{O}_{2}$ with lithium on the vanadium layers switches on lithium intercalation.

Second, the MD simulations indicate facile $\mathrm{Li}^{+}$diffusion in the lithiated composition, $\mathrm{Li}_{1.07+y} \mathrm{~V}_{0.93} \mathrm{O}_{2}$, with a low activation barrier $(0.32 \mathrm{eV})$ for interstitial $\mathrm{Li}^{+}$transport, and diffusion coefficients $\left(D_{\mathrm{Li}}\right)$ of $c a .10^{-9} \mathrm{~cm}^{2} \mathrm{~s}^{-1}$; these values are consistent with other layered oxide electrodes and suggest favourable rate performance. Finally, long-range $\mathrm{Li}^{+}$diffusion is found to be highly anisotropic, largely restricted to within the lithium layers adjacent to vanadium layers that contain lithium ions. Interestingly, there is also evidence of interlayer diffusion via the lithium ions on the vanadium sites, and involving a cooperative interstitial mechanism.

These insights into transport mechanisms and electrode kinetics are valuable in developing strategies for optimizing this low voltage oxide anode.

\section{Acknowledgements}

We acknowledge EPSRC for funding (EP/H019596/1) and the Materials Chemistry consortium (EP/L000202/1) for access to high-end supercomputer resources. PMP would like to thank D. J. Cooke for useful discussions.

\section{Notes and references}

1 J. B. Goodenough, Chem. Mater., 2010, 22, 587.

2 B. L. Ellis, K. T. Lee and L. F. Nazar, Chem. Mater., 2010, 22, 691.

3 M. S. Whittingham, MRS Bull., 2008, 33, 411.

4 M. Armand and J.-M. Tarascon, Nature, 2008, 451, 652.

5 P. G. Bruce, B. Scrosati and J. M. Tarascon, Angew. Chem., Int. Ed., 2008, 47, 2930; B. Scrosati, J. Hassoun and Y.-K. Sun, Energy Environ. Sci., 2011, 4, 3287.

6 M. R. Palacín, Chem. Soc. Rev., 2009, 38, 2565.

7 M. M. Thackeray, C. Wolverton and E. D. Isaacs, Energy Environ. Sci., 2012, 4, 7854.

8 J. Liu, J.-G. Zhang, Z. Yang, J. P. Lemmon, C. Imhoff, G. L. Graff, L. Li, J. Hu, C. Wang, J. Xiao, G. Xia, V. V. Viswanathan, S. Baskaran, V. Sprenkle, X. Li, Y. Shao and B. Schwenzer, Adv. Funct. Mater., 2013, 23, 929.

9 N. S. Choi, J. S. Kim, R. Z. Yin and S. S. Kim, Mater. Chem. Phys., 2009, 116, 603.

10 G. Zhu, Y.-G. Wang and Y.-Y. Xia, Energy Environ. Sci., 2012, 5, 6652 . 
11 M. V. Reddy, G. V. Subba Rao and B. V. R. Chowdari, Chem. Rev., 2013, 113, 5364.

12 L. Ji, Z. Lin, M. Alcoutlabi and X. Zhang, Energy Environ. Sci., 2011, 4, 2682.

13 J. H. Song, H. J. Park, K. J. Kim, Y. N. Jo, J.-S. Kim, Y. U. Jeong and Y. J. Kim, J. Power Sources, 2010, 195, 6157.

14 S.-S. Kim, J. Kim, M. Koike and N. Kobayashi, 14th International Meeting on Lithium Batteries, Tianjin, Abstract \#20, 2008.

15 S.-S. Kim, Y. Nitta, T. I. Nedoseykina and J.-C. Lee, US Pat., 2006/0088766, 2006.

16 A. R. Armstrong, C. Lyness, P. M. Panchmatia, M. S. Islam and P. G. Bruce, Nat. Mater., 2011, 10, 223.

17 W.-T. Kim, Y. U. Jeong, H. C. Choi, Y. J. Lee, Y. J. Kim and J. H. Song, J. Power Sources, 2013, 221, 366.

18 F. Pourpoint, X. Hua, D. S. Middlemiss, P. Adamson, D. Wang, P. G. Bruce and C. P. Grey, Chem. Mater., 2012, 24, 2880.

19 J. Yi, J. Key, F. Wang, Y.-G. Wang, C. Wang and Y.-Y. Xia, Electrochim. Acta, 2013, 106, 534; J. M. Gaudet and J. R. Dahn, Can. J. Phys., 2013, 91, 444.

20 Y. C. K. Chen-Wiegart, P. Shearing, Q. Yuan, A. Tkachuk and J. Wang, Electrochem. Commun., 2012, 21, 58.

21 C. A. J. Fisher and M. S. Islam, J. Mater. Chem., 2008, 18, 1208; M. Schroeder, C. Eames, D. A. Tompsett, G. Lieser and M. S. Islam, Phys. Chem. Chem. Phys., 2013, 15, 20473.

22 M. S. Islam, D. J. Driscoll, C. A. J. Fisher and P. R. Slater, Chem. Mater., 2005, 17, 5085; G. R. Gardiner and M. S. Islam, Chem. Mater., 2010, 22, 1242; N. Kuganathan and M. S. Islam, Chem. Mater., 2009, 21, 5196.

23 S. Lee and S. S. Park, J. Phys. Chem. C, 2012, 116, 6484; C. Tealdi, C. Spreafico and P. Mustarelli, J. Mater. Chem., 2012, 22, 24870; S. Adams and R. P. Rao, Solid State Ionics, 2011, 184, 57; M. Vijayakumar, S. Kerisit, K. M. Rosso, S. D. Burton, J. A. Sears, Z. Yang, G. L. Graff, J. Liu and J. Hu, J. Power Sources, 2011, 196, 2211; S. E. Boulfelfel, G. Seifert and S. Leoni, J. Mater. Chem., 2011, 21, 16365.

24 M. Salanne, M. Marrocchelli and G. W. Watson, J. Phys. Chem. C, 2012, 116, 18618.

25 Computer Modelling in Inorganic Crytallography, ed. C. R. A. Catlow, Academic Press, San Diego, 1997.

26 M. S. Islam and C. A. J. Fisher, Chem. Soc. Rev., 2014, 43, 185.
27 W. Smith, C. W. Yong and P. M. Rodger, Mol. Simul., 2002, 28, 385; S. Nóse, J. Chem. Phys., 1984, 81, 511; W. G. Hoover, Phys. Rev. A: At., Mol., Opt. Phys., 1985, 31, 1695.

28 J. D. Gale, J. Chem. Soc., Faraday Trans., 1997, 93, 629.

29 N. F. Mott and M. J. Littleton, Trans. Faraday Soc., 1938, 34, 485 .

30 C. Tealdi, P. Mustarelli and M. S. Islam, Adv. Funct. Mater., 2010, 20, 3874; E. Kendrick, J. Kendrick, K. S. Knight, M. S. Islam and P. R. Slater, Nat. Mater., 2007, 6, 871; P. M. Panchmatia, A. Orera, G. J. Rees, M. E. Smith, J. V. Hanna, P. R. Slater and M. S. Islam, Angew. Chem., Int. Ed., 2011, 50, 9328; A. Chroneos, D. Parfitt, J. A. Kilner and R. W. Grimes, J. Mater. Chem., 2010, 20, 266.

31 K. Hoang and M. D. Johannes, J. Mater. Chem. A, 2014, 2, 5224; F. X. Hart and J. B. Bates, J. Appl. Phys., 1998, 83, 7560 .

32 K. Persson, V. A. Sethuraman, L. J. Hardwick, Y. Hinuma, Y.-S. Meng, A. van der Ven, V. Srinivasan, R. Kostecki and G. Ceder, J. Phys. Chem. Lett., 2010, 1, 1176; S. Bhattacharya, A. R. Riahi and A. T. Alpas, Carbon, 2014, 67, 597; D. R. Baker and M. W. Verbugge, J. Electrochem. Soc., 2012, 159, A1341; P. Maire, H. Kaiser, W. Scheifele and P. Novak, J. Electroanal. Chem., 2010, 644, 127.

33 Q. S. Wang, J. H. Sun, C. H. Chen and X. M. Zhou, J. Therm. Anal. Calorim., 2008, 92, 563; M. Park, X. Zhang, M. Chung, G. B. Less and A. M. Sastry, J. Power Sources, 2010, 195, 7904; P. Jeevan-Kumar, K. Jayanth-Babu, O. M. Hussain and C. M. Julien, Solid State Ionics, 2013, 19, 421; M. Shui, S. Gao, J. Shu, W. D. Zheng, D. Xu, L. L. Chen, L. Feng and Y. L. Ren, Solid State Ionics, 2013, 19, 47; W. C. West, J. Soler, M. C. Smart, B. V. Ratnakumar, S. Firdosy, V. Ravi, M. S. Anderson, J. Hrbacek, E. S. Lee and A. Manthiram, J. Electrochem. Soc., 2011, 158, A883-A889; M. Gozu, K. Swierczek and J. Molenda, J. Power Sources, 2009, 194, 38; K. M. Shaju, G. V. S. Rao and B. V. R. Chowdari, J. Electrochem. Soc., 2004, 151, A1324.

34 F. Nobili, S. Dsoke, F. Croce and R. Marassi, Electrochim. Acta, 2005, 50, 2307.

35 K. Nakamura, H. Ohno K. Okamura, Y. Michihiro, I. Nakabayashi and T. Kanashiro, Solid State Ionics, 2000, 135, 143. 